\title{
PEDILANTHUS DIAZLUNANUS (EUPHORBIACEAE), ESPECIE NUEVA DEL SUR DE JALISCO, MEXICO
}

\author{
Jose Aquileo Lomeli Sencion \\ Eduardo Sahagun Godinez \\ Jardín Botánico y Herbario GUADA \\ Escuela de Biología \\ Universidad Autónoma de Guadalajara \\ Apartado postal 1-440 \\ 44100 Guadalajara, Jal., México
}

\begin{abstract}
RESUMEN
Se describe Pedilanthus diazlunanus, planta xerófila del municipio de Tolimán, Jalisco. Esta nueva especie parece estar cercanamente relacionada con $P$. tehuacanus y $P$. tomentellus, con las que comparte la presencia de látex de color amarillo, espolón reducido y número de glándulas medias.
\end{abstract}

\begin{abstract}
Pedilanthus diazlunanus, a xerophilous species, is described from Toliman in southern Jalisco. This new species appears to be a close ally of $P$. tehuacanus and $P$. tomentellus because of the shared presence of yellow milky juice, short spur and two medial glands.
\end{abstract}

Como resultado de las exploraciones científicas que realiza el personal del Jardín Botánico "Jorge Victor Eller T." y el Herbario GUADA, ambos de la Universidad Autónoma de Guadalajara, se han realizado descubrimientos interesantes. Tal es el caso de Pedilanthus diazlunanus, especie que en este trabajo se presenta como nueva para la ciencia y cuya descripción fue hecha de especímenes que se mantienen en cultivo en el mencionado jardín, registrados con el número 87-01052.

Siguiendo el criterio de Dressler (1957), $P$. diazlunanus Lomelí et Sahagún queda comprendido dentro del grupo de $P$. bracteatus (Jacq.) Boiss., en el cual se incluye también a $P$. macrocarpus Bentham, $P$. tomentellus Robins. et Greenm. y P. tehuacanus Brandegee. Hasta donde es conocido, los cuatro primeros taxa se encuentran distribuidos en la vertiente del Pacífico Mexicano; la última especie de este grupo, $P$. tehuacanus, es endémica del estado de Puebla en la región oriente del país.

Pedilanthus diazlunanus Lomelí et Sahagún, sp. nov. Fig. 1

Frutex caespitosa 1-1.5 m alta, ramificatione basali, latice flavo; caules succulenti, erecti vel deflexi, maturitate glabri, juventute tomentosi; folia coriacea, caduca, laminis ovatis vel lanceolatis, $1.3-7.5 \mathrm{~cm}$ longis, $0.9-4.5 \mathrm{~cm}$ latis, supra glabrescentibus, nervis primariis conspicuis $6-11$, infra tomentosis, petiolo usque ad $9 \mathrm{~mm}$ longo, stipulis vestigialibus; cyathia 


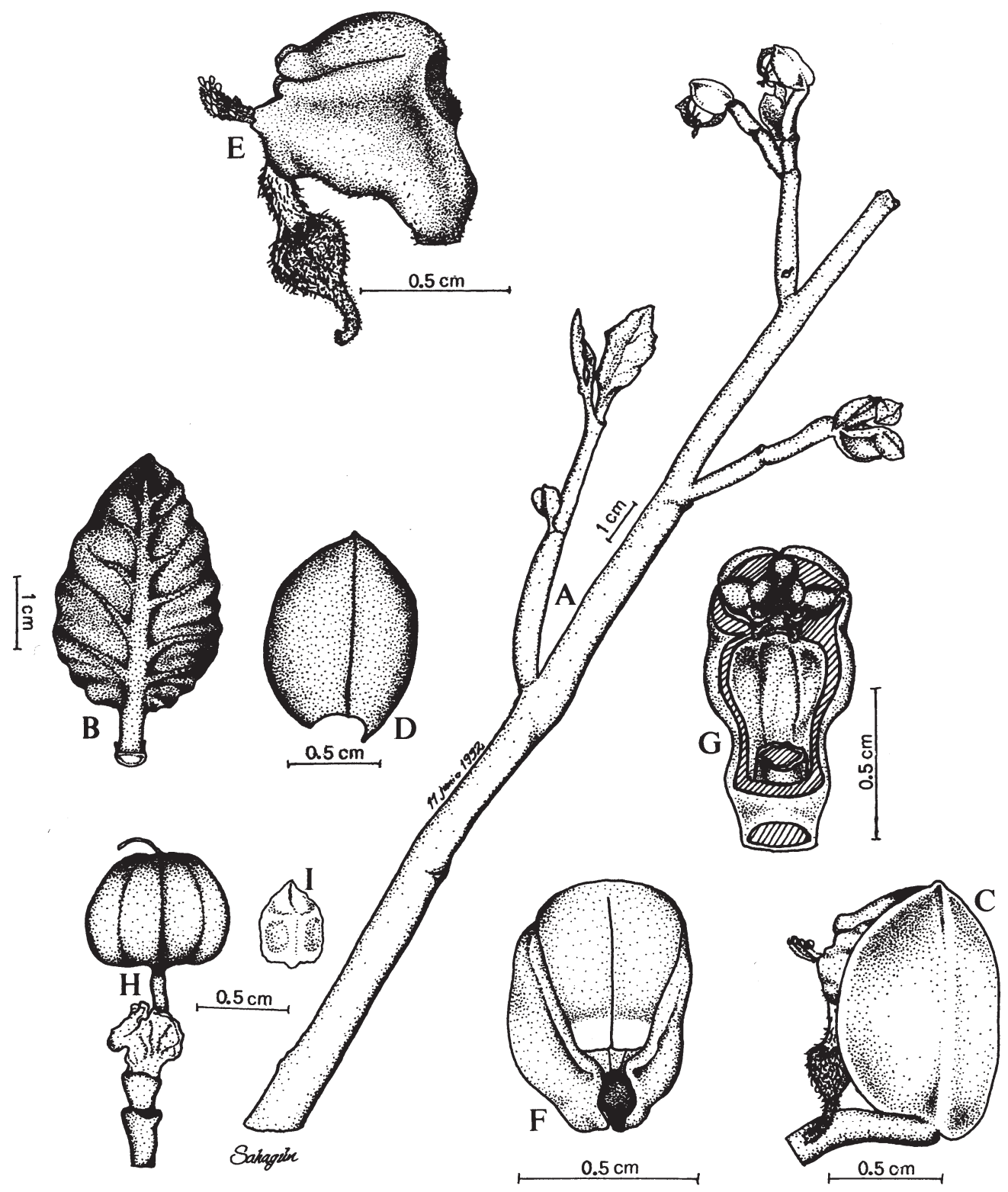

Fig. 1. Pedilanthus diazlunanus Lomelí et Sahagún. A. Rama con hojas y ciatios; B. Hoja mostrando el haz, la nervadura ha sido enfatizada; C. Brácteas cubriendo el ciatio, vista lateral; D. Bráctea extendida; E. Ciatio, vista lateral; F. Involucro, vista dorsal; G. Involucro en sección longitudinal, las flores estaminadas y pistilada han sido removidas. Nótese en la parte superior las glándulas medias y los lóbulos accesorios; H. Cápsula en posición natural con el involucro y estilo persistentes; I. Semilla, vista ventral. 
terminalia, abortu in monochasiis disposita, bracteis oblongis usque ad suborbicularibus, cucullatis, 7-12 mm longis, 6-9 mm latis, base obliquis, apice obtuse apiculatis, nervo inconspicuo, caducis; pedunculus usque ad $2.5 \mathrm{~mm}$ longus, glaber vel tomentulosus; cyathium glabrum vel pilosiusculum, tubo involucrali $4-6 \mathrm{~mm}$ longo, lobis principalibus transverse oblongis, apice irregulariter laciniatis, lobis accesoriis oblongis, puberulis, lobis lateralibus imbricatis, lobo medio insidentibus; calcar nullo modo projectum, vinaceum vel viridulum, sessile, lobis lateralibus longe triangularibus, lobis mediis deltoideo-oblongis, 5$6 \mathrm{~mm}$ longis, confluentibus; glandulae binae mediae globoso-oblongae, obliquae; flores staminei 16-24; ovarium 1-2.5 mm diametro, dense tomentulosum; capsula subsphaerica vel triquetra, 6-8 mm longa, 8-9 mm diametro, pericarpio solido, vix tomentoso, dehiscenti; semina oblongo-ovoidea, 4-5 mm longa, 3-3.5 mm lata, angulata; embryo spathulatus, 3.5 $\mathrm{mm}$ longus, endospermium oleaginosum.

Arbusto cespitoso de 1-1.5 m de alto, con ramificaciones basales y látex de color amarillo; tallos suculentos hasta de $1.5 \mathrm{~cm}$ de diámetro, de color verde o verde-azuloso, erectos o deflexos, simples o con 2-3 ramificaciones hacia su parte media superior, con cicatrices foliares semilunares, los nudos separados entre sí $1.5-6 \mathrm{~cm}$, los tallos adultos glabros y los jóvenes tomentulosos; hojas coriáceas, caducas, lámina ovada o lanceolada, $1.3-7.5 \mathrm{~cm}$ de largo, 0.9-4.5 cm de ancho, base redondeada, ápice agudo o mucronulado, borde ondulado o entero, haz glabrescente con 6-11 nervios primarios más o menos conspicuos, ocasionalmente con dos costillas a los lados de la nervadura central, envés tomentoso con sólo la vena central visible, pecíolo hasta de $9 \mathrm{~mm}$ de largo y $3.3 \mathrm{~mm}$ de diámetro, densamente tomentoso; estípulas vestigiales de color de vino tinto, aprox. $1 \mathrm{~mm}$ de largo; ciatios terminales, en dicasios o más frecuentemente en monocasios por aborción, entrenudos de $2-22 \mathrm{~mm}$ de longitud, tomentosos o glabrescentes, brácteas oblongas a suborbiculares, cuculadas, $7-12 \mathrm{~mm}$ de largo, 6-9 $\mathrm{mm}$ de ancho, verdeamarillentas o verde-rojizas, tomentosas por fuera y lanuginosas por dentro, caducas, base oblicua, ápice obtuso-apiculado, nervadura inconspicua; pedúnculo de menos de $2.5 \mathrm{~mm}$ de largo, glabro o tomentuloso; ciatio de color verde-amarillento o verde-rojizo, glabro $\circ$ pilosiúsculo, tubo involucral 4-6 $\mathrm{mm}$ de largo, lóbulos principales de color amarillento, transversalmente oblongos, ápices irregularmente laciniados y libres ventralmente por espacio de 2-3 mm; lóbulos accesorios unidos en su base, oblongos, de menos de $2 \mathrm{~mm}$ de largo y $1 \mathrm{~mm}$ de ancho, pubérulos en su porción media basal, los lóbulos laterales imbricados sobre el lóbulo medio el cual es más ancho y corto, ápices enteros o aserrados; espolón no proyectado, casi ausente, de color de vino tinto o verde, sésil sobre el tubo involucral a aprox. 7-8 $\mathrm{mm}$ del pedúnculo, aprox. $4.5 \mathrm{~mm}$ de ancho en el ápice, redondeado, lóbulos laterales del espolón largamente triangulares, lóbulos intermedios deltoideooblongos, aprox. 5-6 mm de largo desde el ápice del espolón, libres por espacio de 3$4.5 \mathrm{~mm}$, el ápice de color amarillo o verde, truncado y a manera de callo especialmente en la superficie abaxial, aprox. $2 \mathrm{~mm}$ de ancho en la base y $1 \mathrm{~mm}$ en el ápice, el margen confluente, ciliado, 2 glándulas medias globoso-oblongas, oblicuas, aprox. $1 \mathrm{~mm}$ de largo; flores estaminadas 16-24, pedicelos 1.5-4 mm de largo, glabros, filamentos aprox. 1-2 mm de largo, glabros o pilosos; pedicelo pistilado 1-1.5 mm de diámetro, glabro o escasamente tomentoso, $5 \mathrm{~mm}$ de largo, ovario aprox. 1-2.5 mm de diámetro, deltoide, densamente tomentoso, tomento de color blanco-amarillento, estilo 1-2 $\mathrm{mm}$ de largo, escasamente tomentoso, divisiones estigmáticas 3 , aprox. $1 \mathrm{~mm}$ de largo, profundamente bífidas; cápsula 
subesférica o triquetra, erecta por extensión secundaria del pedicelo, 6-8 $\mathrm{mm}$ de largo, 8-9 $\mathrm{mm}$ de diámetro, escasamente tomentosa, de color amarillo pálido o rojizo, disiliente en 6 valvas, pericarpo sólido, involucro y estilo persistentes; semillas 1-3, testa de color pardo obscuro con granulaciones de color amarillo terroso, oblongo-ovoides, 4-5 $\mathrm{mm}$ de largo, aprox. 3-3.5 mm de ancho, base truncada o cóncava, ápice agudo, hilo subterminal de 1-2 $\mathrm{mm}$ de largo, micrópilo inconspicuo, rafe a veces prolongado hasta la base, presentan ventralmente dos concavidades laterales y una apical, dorsalmente una costilla media y dos laterales; embrión espatulado, aprox. $3.5 \mathrm{~mm}$ de largo, endospermo oleaginoso.

Nombres comunes: resistol, candelilla.

TIPO: México, Jalisco, barranca El Huisichi, aprox. $15 \mathrm{~km}$ al SE de Tolimán, a $19^{\circ}$ $34^{\prime} 30$ " latitud $\mathrm{N}$ y $103^{\circ} 52^{\prime} 00^{\prime \prime}$ longitud $\mathrm{O}$, bosque tropical deciduo a una altitud de 800 m, 18.IX.1987; ejemplares preparados de plantas cultivadas en el Jardín Botánico "Jorge Victor Eller T." de la Universidad Autónoma de Guadalajara el 18.VIII.1992, Lomelí \& Díaz s.n. Holotipo (GUADA); Isotipos serán distribuidos a los siguientes herbarios: ENCB, F, G, GH, IEB, K, MEXU, MICH y US. Otros especímenes vistos: barranca El Huisichi municipio de Tolimán, 19.X.1987, Díaz Luna s.n. (GUADA); camino Tolimán-EI Huisichi, en ladera de barranca, E. Sahagún et al. 75 (GUADA); terracería adelante de San Pedro, a un lado de "La Taza" municipio de Tolimán, 10.V.1991, ejemplares prensados de plantas cultivadas en el Jardín Botánico el 17.IX.1992, León Maldonado et al. s.n. (GUADA).

Pedilanthus diazlunanus parece estar estrechamente emparentado con $P$. tehuacanus y $P$. tomentellus, con las que comparte la presencia de látex de color amarillo, espolón muy reducido y dos glándulas medias. Entre $P$. diazlunanus y $P$. tehuacanus la afinidad es particularmente evidente al comparar la forma del involucro; sin embargo, existen numerosas diferencias entre ambos (Cuadro 1; Fig. 2) que justifican el reconocimiento de este nuevo taxon. $P$. tomentellus difiere de la nueva especie principalmente por su hábito arbustivo de mayor altura y las brácteas de color rojo de 2.2$3.5 \mathrm{~cm}$ de largo. $P$. macrocarpus, la entidad filogenéticamente más alejada del grupo de $P$. bracteatus, es también la más distante de $P$. diazlunanus, así lo sugiere en la primera especie la presencia de látex color blanco, involucro de color rojizo con el espolón conspicuamente proyectado y 4 glándulas medias. Dressler (1957) menciona que $P$. tehuacanus es de particular interés por el tamaño reducido de los ciatios, característica que a su parecer sugiere polinizaciòn por insectos en un género típicamente polinizado por aves; en este respecto, $P$. diazlunanus parece presentar un estado aún más avanzado en tal dirección, con mayor reducción en el tamaño de los ciatios y en el número de glándulas. El epíteto específico del taxon aqui propuesto es dado en memoria del Biólogo Carlos Luis Díaz Luna, colector y botánico fundador del herbario GUADA de la Escuela de Biología.

$P$. diazlunanus es una especie típicamente xerófila, que crece formando grandes colonias en las laderas y barrancas. Las plantas cultivadas en el jardín botánico que han sido utilizadas para la descripción de este nuevo taxon, florecen durante casi todo el año. La dehiscencia de los frutos ocurre por torsión explosiva de sus valvas dispersando las semillas a considerable distancia. 


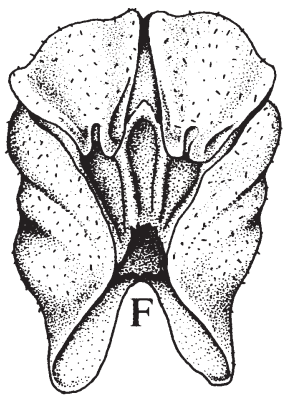

$0.5 \mathrm{~cm}$
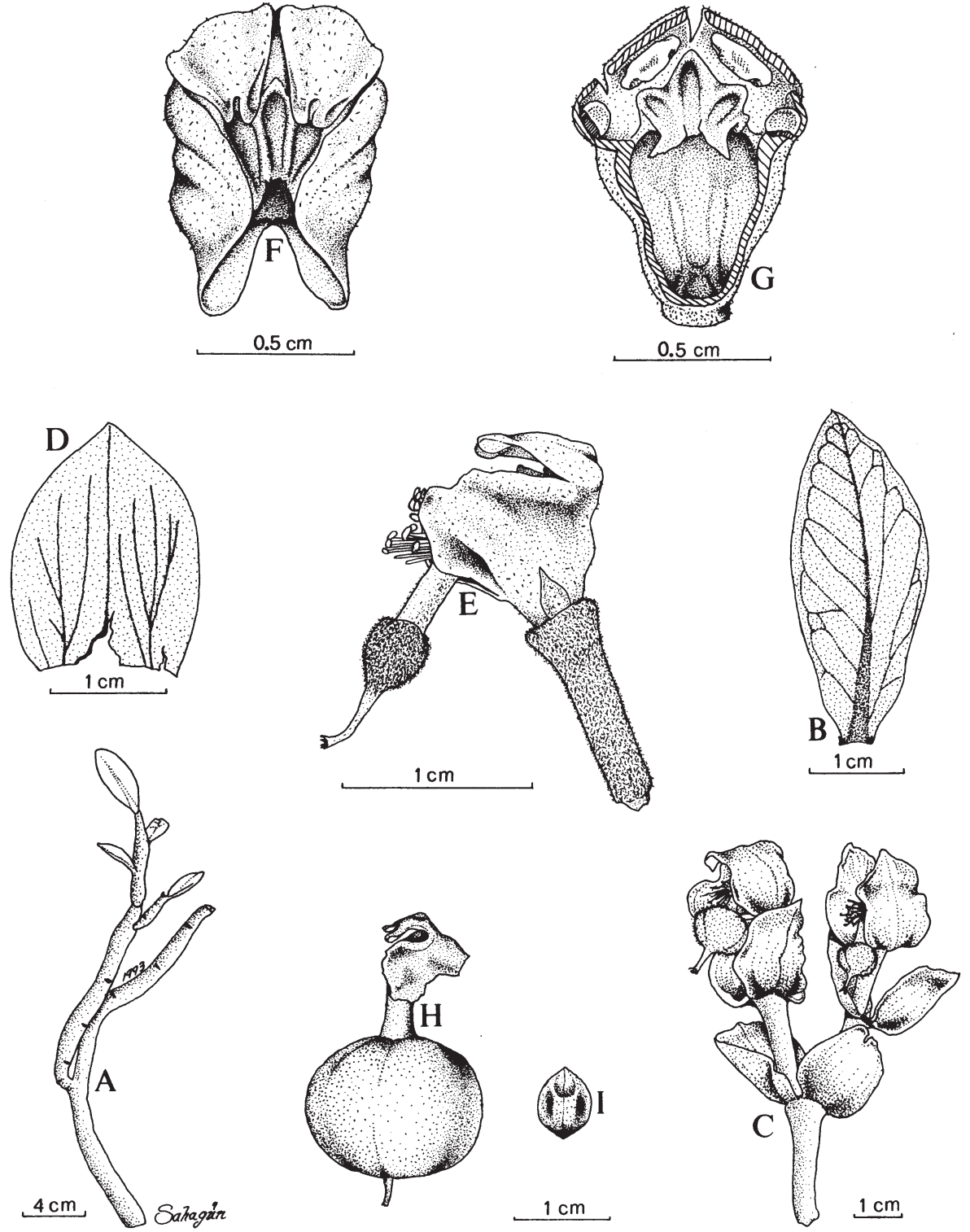

Fig. 2. Pedilanthus tehuacanus Brandegee. A. Rama de planta juvenil; B. Hoja de planta juvenil; C. Dicasio; D. Bráctea extendida; E. Ciatio, vista lateral; F. Involucro, vista dorsal; G. Involucro en sección longitudinal, nótense en la parte superior las glándulas laterales y medias y los lóbulos accesorios; $\mathrm{H}$. Cápsula en posición natural con el involucro y estilo persistentes; I. Semilla, vista ventral. A-B de ejemplar cultivado en el jardín botánico; C-I, de material preservado en líquido. Todos basados en Lomell s.n., 28.VIII.1992 (GUADA). 
Acta Botánica Mexicana (1993), 25:15-20

Cuadro 1. Principales diferencias entre $P$. diazlunanus y $P$. tehuacanus.

\begin{tabular}{|c|c|}
\hline$P$. diazlunanus & P. tehuacanus \\
\hline $\begin{array}{l}\text { Arbusto } 1-1.5 \mathrm{~m} \text { de alto, con inflorescencias } \\
\text { incospicuas }\end{array}$ & $\begin{array}{l}\text { Arbusto } 1.5-2 \mathrm{~m} \text { de alto, con inflorescencias } \\
\text { conspicuamente coloreadas }\end{array}$ \\
\hline Inflorescencias generalmente en monocasios & Inflorescencias generalmente en dicasios \\
\hline $\begin{array}{l}\text { Brácteas de color verde-amarillento o verde- } \\
\text { rojizo, } 7-12 \mathrm{~mm} \text { de largo, base oblicua, ápice } \\
\text { obtuso-apiculado, nervadura inconspicua. Már- } \\
\text { genes separados durante la antesis }\end{array}$ & $\begin{array}{l}\text { Brácteas de color rosado, } 12-30 \mathrm{~mm} \text { de largo, } \\
\text { base simétrica, ápice agudo, nervadura } \\
\text { conspicua. Márgenes dorsal y apical connados } \\
\text { durante la antesis }\end{array}$ \\
\hline $\begin{array}{l}\text { Lóbulos accesorios sin callos curvados en la } \\
\text { base }\end{array}$ & $\begin{array}{l}\text { Lóbulos accesorios con callos curvados en la } \\
\text { base. Los callos con forma de " } u \text { " invertida }\end{array}$ \\
\hline $\begin{array}{l}\text { Glándulas medias oblicuas, aprox. } 1 \mathrm{~mm} \text { de } \\
\text { largo, ubicadas casi en la base de los lóbulos } \\
\text { accesorios }\end{array}$ & $\begin{array}{l}\text { Glándulas medias curvadas, aprox. } 2.5 \mathrm{~mm} \text { de } \\
\text { largo, distantes aprox. } 1 \mathrm{~mm} \text { de la base de los } \\
\text { lóbulos accesorios }\end{array}$ \\
\hline Glándulas laterales ausentes & Glándulas laterales presentes \\
\hline $\begin{array}{l}\text { Cápsula de color amarillo pálido o rojizo, } \\
\text { subesférica o triquetra, } 8-9 \mathrm{~mm} \text { de diámetro, } \\
\text { pericarpo sólido. Predehiscencia y dehiscencia } \\
\text { heliófilas }\end{array}$ & $\begin{array}{l}\text { Cápsula de color rosado, cónico-esférica, } \\
18-22 \mathrm{~mm} \text { de diámetro, pericarpo pulposo. } \\
\text { Predehiscencia y dehiscencia geófilas }\end{array}$ \\
\hline $\begin{array}{l}\text { Semillas oblongo-ovoides, } 4-5 \mathrm{~mm} \text { de largo, 3- } \\
3.5 \mathrm{~mm} \text { de ancho, angulosas }\end{array}$ & $\begin{array}{l}\text { Semillas ovoides a subesféricas, } 7-8 \mathrm{~mm} \text { de } \\
\text { largo, } 6 \mathrm{~mm} \text { de ancho, no angulosas }\end{array}$ \\
\hline Altitud entre $750-800 \mathrm{~m}$ & Altitud entre $1750-1800 \mathrm{~m}$ \\
\hline
\end{tabular}

\section{AGRADECIMIENTOS}

Los autores expresan su agradecimiento al Dr. Robert L. Dressler por la revisión del manuscrito, al Dr. Jerzy Rzedowski por la diagnosis latina y a los Biólogos René A. León Maldonado y Darío Narváez Peláez por el manejo electrónico de la información. También hacen público su agradecimiento a las autoridades de la Universidad Autónoma de Guadalajara por el apoyo económico para la realización de los viajes de campo.

\section{LITERATURA CITADA}

Dressler, R. L. 1957. The genus Pedilanthus (Euphorbiaceae). Contr. Gray Herbarium 182: 1-188. 